\title{
Febrile seizures
}

\author{
Lynette G Sadleir, ${ }^{1}$ Ingrid E Scheffer ${ }^{2}$
}

${ }^{1}$ Department of Paediatrics, Wellington School of Medicine, University of Otago, Wellington, New Zealand

${ }^{2}$ Departments of Medicine and Paediatrics, University of Melbourne, Austin Health and Royal Children's Hospital, Melbourne, Australia

Correspondence to: I Scheffer scheffer@unimelb.edu.au

\section{BMJ 2007:334:307-11} doi: 10.1136/bmi.39087.691817.AE
Seizures associated with fever are a common paediatric problem. Differentiation of febrile seizures from acute symptomatic seizures secondary to central nervous system infection or seizures triggered by fever in children with epilepsy is essential. The syndrome of febrile seizures is defined as seizures associated with fever in the absence of central nervous system infection or acute electrolyte imbalance in a young child. ${ }^{\mathrm{w} 1}$ The prevalence of febrile seizures is between $3 \%$ and $8 \%$ in children up to 7 years of age. ${ }^{1 \text { w2 }}$ Variation in prevalence relates to differences in case definitions, ascertainment methods, geographical variation, and cultural factors. Here we discuss the investigation, management, and outcome of febrile seizures.

\section{Sources and selection criteria}

We searched Medline, Embase, and the Cochrane Collaboration from 2000 onwards by using the medical subject heading "seizures, febrile" or key words "febrile convulsions" or "febrile seizures". We searched the same databases before that date, focusing on the medical subject headings only. We selected relevant articles from the abstracts and hand searched these for other pertinent publications.

Why and at what age do children have febrile seizures? Febrile seizures result from a combination of genetic and environmental factors. ${ }^{2}$ Of children with febrile seizures, $24 \%$ have a family history of febrile seizures and $4 \%$ have a family history of epilepsy. ${ }^{3}$ Although polygenic inheritance is usual, a small number of families exist in whom the inheritance of febrile seizures is autosomal dominant, and several chromosomal loci and a few genes have been identified. ${ }^{4}$ Mutations in sodium channel and $\gamma$-aminobutyric acid A receptor genes have been identified in children with febrile seizures, ${ }^{\text {w3 }}{ }^{\mathrm{w} 4}$ suggesting that genes coding for ion channels are likely to underlie the syndrome.

Febrile seizures are defined as occurring between 6 months and 6 years of age. ${ }^{5}$ The median age of onset is 18 months, and half of children present between 12 and 30 months. $^{3}$

\section{What is the relation of the fever to the seizure?}

The fever associated with a febrile seizure is usually defined by a temperature of at least $38^{\circ} \mathrm{C} .{ }^{3}$ No

\section{SUMMARY POINTS}

Febrile seizures are the most common seizure disorder They are benign and have a normal cognitive outcome Febrile seizures recur in a third of children and are associated with a low risk of epilepsy

Risk factors for epilepsy include complex febrile seizure, neurological abnormality, and family history of epilepsy Febrile seizures are prolonged in $9 \%$ of cases; these should be treated with buccal or intranasal midazolam

evidence exists that febrile seizures are more likely to occur with the maximal rate of temperature rise, although this is often quoted. ${ }^{6}$ Febrile seizures may occur before the fever is apparent and early or late in the course of a febrile illness. ${ }^{\text {w5 }}$

An entity of afebrile convulsions in young children with mild gastroenteritis is increasingly recognised. This disorder was initially observed in Asian countries, but white children from the United Kingdom have recently been reported with the condition. ${ }^{\text {w6 }}$ Whether the racial differences are caused by underlying genetic or environmental factors or relate to under-recognition is unclear. A large case series found that these children present with clusters of generalised or focal seizures with and without fever over several days in the setting of viral gastroenteritis. ${ }^{7}$ w6 Children do well without recurrence of seizures and have normal development. Compared with children with febrile seizures, these children have less of a family history of seizures, a lower recurrence rate, and more clustering of attacks. ${ }^{7}$ w

\section{Features and duration of febrile seizures}

Febrile seizures are predominantly brief, generalised tonic-clonic seizures, and 4-16\% have focal features according to epidemiological studies. ${ }^{189}$ More recently, febrile myoclonic seizures have been recognised. ${ }^{10}$ Febrile myoclonus has a similar age of onset to convulsive febrile seizures and is associated with a family history of febrile seizures. ${ }^{10}$

In $87 \%$ of children, the duration of the febrile seizure is less than 10 minutes; seizures last more than 15 minutes in $9 \%$ of children. ${ }^{11}$ Febrile status epilepticus ( $>30$ minutes' duration) occurs in 5\% children and is more likely to have focal features. ${ }^{11} \mathrm{~A}$ prolonged febrile seizure is a risk factor for further prolonged attacks. ${ }^{11}$ 


\begin{tabular}{lccc}
\hline Table 1 | Risk factors for seizures & & & \\
Associated features and risk factors & First febrile seizure & Recurrent febrile seizures & Epilepsy \\
Attendance at day care & Yes & Yes & Not studied \\
\hline High temperature during illness & Yes & No & No \\
\hline Neonatal nursery stay 30 days & Yes & Not studied & Not studied \\
\hline Family history of febrile seizures & Yes & Yes & No \\
\hline Age $<18$ months at first seizure & NA & Yes & No \\
\hline Lower temperature close to $38^{\circ}$ C during seizure & NA & Yes & No \\
\hline Short duration («1 hour) of fever before seizure & NA & Yes & Yes \\
\hline Prolonged seizure (>15 minutes) & NA & No & Yes \\
\hline Multiple seizures in 24 hours & NA & No & Yes \\
\hline Focal features of seizure & NA & No & Yes \\
\hline Family history of epilepsy & No & No & Yes \\
\hline Neurological abnormality & Yes & No & Yes \\
\hline NA=not applicable & & &
\end{tabular}

\section{When do febrile seizures recur?}

Thirty per cent of children have recurrent febrile seizures during subsequent illnesses. ${ }^{3}$ Risk factors for recurrence (as distinct from risk of a first febrile seizure) include onset before 18 months, lower temperature close to $38^{\circ} \mathrm{C}$, shorter duration of fever ( $<1$ hour) before the seizure, and a family history of febrile seizures ${ }^{12} 13$ w7 $w 8$ (table 1). Of children who have all these risk factors, $76 \%$ will have a recurrence of febrile seizure compared with $4 \%$ without risk factors. ${ }^{12}$

\section{What is the risk of epilepsy occurring?}

The vast majority of children who present with febrile seizures do not develop epilepsy. Febrile seizures are classified as simple or complex; complex febrile seizures are associated with an increased risk of epilepsy. Complex febrile seizures are defined by at least one of the following features: duration longer than 15 minutes, multiple seizures within 24 hours, and focal features. ${ }^{1}$ These features are absent in simple febrile seizures, which make up $75 \%$ of attacks. ${ }^{9}$

Large prospective cohort studies of children have identified other risk factors for epilepsy, including neurological abnormality, a family history of epilepsy, and short duration of fever ( $<1$ hour) before the seizure (table 1). ${ }^{1811}$ Children with no risk factors have a $2.4 \%$ chance of developing afebrile seizures by 25 years compared with $1.4 \%$ for the general population. ${ }^{9}$ Children with a history of at least one complex feature, a neurological abnormality, and a family history have a $10 \%$ risk of developing epilepsy by the age of $7 .{ }^{1}$ Prolonged febrile seizures increase the incidence of epilepsy to $21 \%$. ${ }^{\text {w9 }}$ For children with all three features of a complex febrile seizure, the risk increases to $49 \% .^{9}$

The relation of epilepsy to seizures with fever is complex; three different scenarios deserve consideration (figure). The first is where the seizure with fever is essentially the onset of the epilepsy syndrome. The best example is severe myoclonic epilepsy of infancy (or Dravet syndrome), in which infants classically present with febrile status epilepticus at around 6 months. The syndromic diagnosis is not initially apparent until the infant later develops afebrile seizures. Another example is the syndrome of "febrile seizures plus," in which seizures with fever persist beyond the age of 5 years or afebrile seizures also occur. By definition, these children have epilepsy and do not fit the definition of febrile seizures, but they carry a similarly good prognosis. ${ }^{\text {w10 }}$

In the second scenario, a period of freedom from seizures follows febrile seizures before the development of a specific epilepsy syndrome such as childhood absence epilepsy. In the third scenario, the child has previously had afebrile seizures and has a diagnosis of epilepsy and then subsequently presents with seizures with fever. These seizures are triggered by fever; these are not febrile seizures but may be confused with them.

Are febrile seizures and hippocampal sclerosis related? A highly controversial area is whether prolonged febrile seizures cause hippocampal sclerosis and intractable temporal lobe epilepsy. Video-electroencephalograph controlled studies of immature rats show that prolonged seizures induced by fever lead to hippocampal damage and spontaneous temporal lobe epilepsy. ${ }^{14}$ Human studies also show that prolonged seizures with fever are associated with hippocampal sclerosis. ${ }^{15-17}$ The hippocampus is hypothesised to be abnormal before the seizure with fever, predisposing the child to prolonged seizures and subsequent development of hippocampal sclerosis. ${ }^{16}{ }^{17}$ The association of prolonged febrile seizures and hippocampal sclerosis is uncommon. For example, a prospective 12 year study of 24 children with prolonged febrile seizures found no hippocampal sclerosis. ${ }^{\text {w11 }}$ Population studies show no increase in temporal lobe epilepsy in children with complex febrile seizures. ${ }^{1 \text { w9 w11 }}$ Given the rarity of hippocampal sclerosis, temporal lobe epilepsy, and febrile status epilepticus, the number of subjects needed to show an effect with epidemiological techniques is beyond the limits of published series. ${ }^{\mathrm{w} 12}$

\section{Do febrile seizures affect cognition and behaviour?}

Febrile seizures have an excellent outcome; population studies show normal intellect and behaviour, even for

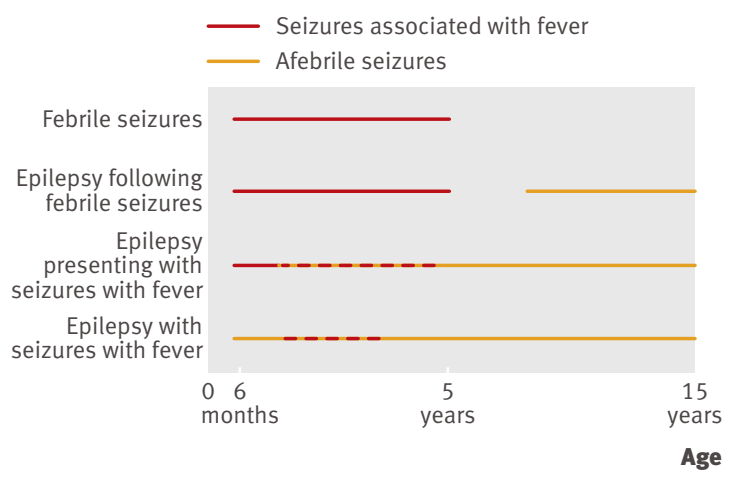

Temporal relation between seizures with fever, febrile seizures, and epilepsy 


\section{TIPS FOR NON-SPECIALISTS}

\section{When does a child need to go to hospital?}

- When meningitis cannot be eliminated by history and examination

- When recovery from seizure is prolonged

-When no cause for the fever is apparent

-When the febrile seizure is complex

-When in a poor psychosocial setting

- When the parents need more support and information than can be provided in a brief consultation

- When no fever is present (this is not a febrile seizure and may be the onset of epilepsy; non-urgent referral is needed)

Important management considerations for children with febrile seizures

- Reassure the family of the benign nature of the disorder

- Educate about prognosis, causes, and what to do if child has another seizure

- Educate parents so that they are not overly anxious about febrile illnesses in their children

\section{Table 2 | Investigations in children with febrile seizures}

\begin{tabular}{lcccc} 
Features & Lumbar puncture & Electroencephalography & Neuroimaging & Biochemistry \\
$\begin{array}{l}\text { Febrile status epilepticus } \\
\text { Age } 18 \text { months }\end{array}$ & Cos & No & No & None \\
\hline $\begin{array}{l}\text { Complex febrile seizure, } \\
\text { otherwise normal }\end{array}$ & Consider & No & No & None \\
\hline $\begin{array}{l}\text { Simple febrile seizure, } \\
\text { otherwise normal }\end{array}$ & No & No & No & None \\
$\begin{array}{l}\text { Neurodevelopmental } \\
\begin{array}{l}\text { abnormality and complex } \\
\text { febrile seizure }\end{array}\end{array}$ & No & No & Possiblynon- \\
$\begin{array}{l}\text { Symptoms and signs } \\
\text { suggestive of meningitis }\end{array}$ & Yes & No & None & \\
\hline
\end{tabular}

children with complex febrile seizures. ${ }^{\mathrm{w} 9 \mathrm{w} 13 \mathrm{w} 14}$ Recent population based prospective case controlled studies from Taiwan found that children who had febrile seizures did at least as well as, if not better than, controls on measures of intelligence, academic achievement, behaviour, and working memory. ${ }^{18}$

\section{What investigations should be done?}

The investigations done on a child with fever should be directed by the degree of illness and the suspected underlying infection. The fact that a child also has a simple febrile seizure in the illness should not modify this approach (table 2).

\section{Lumbar puncture}

When the clinical history suggests meningitis, a lumbar puncture should be done unless contraindications such as signs of raised intracranial pressure with altered conscious state, focal neurological signs, cardiorespiratory compromise, a bleeding diathesis, or infection in the area the needle will traverse are present. ${ }^{\text {w15 }}$ Antibiotics should be started if a contraindication to lumbar puncture is present. ${ }^{13} 19 \mathrm{w} 16$

Meningitis is rare $(0.23 \%)$ in children presenting with seizures and fever in the developed world. ${ }^{\text {w17 }}$ Nevertheless, meningitis presents with seizures in $24 \%$ of children. ${ }^{\text {w18 }}$ In the vast majority of children, meningitis can be ruled out on clinical grounds, rendering a lumbar puncture unnecessary.

Prospective population based studies have found that bacterial meningitis occurs in up to $18 \%$ of children with febrile status epilepticus. ${ }^{20 \text { w19 }}$ Thus in febrile status epilepticus, early parenteral antibiotics have been recommended, followed by a lumbar puncture when safe. ${ }^{\text {w20 }}$

Meningitis is very unlikely in children over the age of 2 years in the absence of a complex febrile seizure, meningeal irritation, or petechiae. ${ }^{\text {w21 }}{ }^{\text {w22 }}$ Children under 2 with meningitis without meningism usually show other features such as being unwell for a few days, vomiting, drowsiness, petechiae, decreased feeding, or complex febrile seizures. ${ }^{\text {w21 w22 }}$ None the less, additional vigilance for meningitis is needed in young children, who may not show meningism, or in any child who presents repeatedly for medical attention. ${ }^{21}$

\section{Electroencephalography}

No evidence exists that epileptiform discharges in children with febrile seizures have any diagnostic or prognostic implications, even in the subgroup with complex febrile seizures. ${ }^{\text {w23 }}$ Therefore, no rationale exists for doing an electroencephalograph in febrile seizures (table 2).

\section{Imaging}

Neuroimaging is not necessary in children with simple febrile seizures. ${ }^{21}$ According to a case series of 71 children, children who present with complex febrile seizures and are otherwise neurologically normal are unlikely to have significant intracranial pathological conditions, such as a space occupying mass lesion, haemorrhage, hydrocephalus, abscess, or cerebral oedema, that need emergency neurosurgical or medical intervention. ${ }^{22}$ Non-urgent magnetic resonance imaging should be considered in children with recurrent complex febrile seizures who have other neurological findings, including abnormal head circumference, significant developmental delay, and persistent focal neurological abnormality. ${ }^{19}$

\section{Blood chemistry analysis}

Routine blood chemistry is not necessary in children with febrile seizures and should only be ordered when specific indications exist. ${ }^{21}$

\section{Management}

Parents may become extremely anxious when their child has febrile seizures, and many think their child is dying. ${ }^{\text {w24 }}$ Concern about the child's future can lead to family stress that interferes with daily family life, such

\section{ONGOING RESEARCH AIMS}

- To determine the interaction of genetic and environmental factors resulting in febrile seizures

- To understand the relation of febrile seizures to specific epilepsy syndromes

- To understand how prolonged febrile seizures lead to hippocampal sclerosis

- To determine the genes involved in the complex inheritance of febrile seizures 


\section{ADDITIONAL EDUCATIONAL RESOURCES}

Reviews

- Shinnar S, Glauser TA. Febrile seizures. J Child Neurol 2002;17(suppl 1):S44-52. A comprehensive general review article on febrile seizures

- Lewis DV. Losing neurons: selective vulnerability and mesial temporal sclerosis. Epilepsia 2005;46(suppl 7):39-44. An indepth discussion about the relation between febrile seizures and mesial temporal sclerosis

- Waruiru C, Appleton R. Febrile seizures: an update. Arch Dis Child 2004;89:751-6. A comprehensive general review article on febrile seizures

- Audenaert D, Van Broeckhoven C, De Jonghe P. Genes and loci involved in febrile seizures and related epilepsy syndromes. Hum Mutat 2006;27:391-401. A recent in-depth update on the genetics of febrile seizures

\section{Websites}

- PRODIGY guidance. Febrile convulsion (www.prodigy.nhs.uk/febrile_convulsion)-general information on febrile seizures

- Emedicine. Febrile seizures (www.emedicine.com/neuro/topic134.htm)-general information on febrile seizures

- Patient UK. Patient Plus: Febrile convulsions (www.patient.co.uk/showdoc/40000513/)-general information on febrile seizures

- Huntingdonshire Primary Care Trust. Primary care guidelines for the prescribing of buccal/intranasal midazolam (Epistatus) for epilepsy in paediatric patients (www.hunts-pct.nhs.uk/default.asp?id=468\&query=midazolam\#highlight) information on prescribing and administering buccal midazolam

\section{Information resources for patients}

- Royal Children's Hospital Melbourne. Febrile convulsion (www.rch.org.au/kidsinfo/factsheets.cfm?doc_id=3722)— Australian based site providing general information on febrile seizures

- Royal Children's Hospital Melbourne. Febrile convulsions-frequently asked questions (www.rch.org.au/kidsinfo/ factsheets.cfm?doc_id=9452)-Australian based site providing general information on febrile seizures

- Royal Children's Hospital Melbourne. Buccal midazolam (www.rch.org.au/kidsinfo/factsheets.cfm?doc_id=9300)_ Australian based site providing information and diagrams on how to administer buccal midazolam from a plastic ampoule

- Toronto Canada Sick Kids Hospital. Febrile seizures (www.aboutkidshealth.ca/clinicalAreas.asp?pageContent=EP-nh202 ) - Canadian based site providing general information on febrile seizures

- National Institute of Neurological Disorders and Stroke. Febrile seizures fact sheet (www.ninds.nih.gov/disorders/febrile_ seizures/detail_febrile_seizures.htm) -US based site providing general information on febrile seizures

- Patient UK. Febrile convulsion (www.patient.co.uk/showdoc/23068735/)-UK based site providing general information on febrile seizures

as the child sleeping in the parents' bed. ${ }^{\text {w25 }}$ Reassurance that the child will not die and education (verbally, in writing, and through support groups) about the cause

\section{A MOTHER'S PERSPECTIVE}

Domenica was 18 months old when she had a febrile seizure in my arms. While breast feeding, she suddenly stopped nursing, her head lolled back, her eyes rolled up, and I was suddenly aware that she had become extremely hot. She went stiff, and I went into a state of stupefaction and disbelief. What was happening? My brain seemed to take a long time to compute. I rushed into the next room and screamed to my husband, "Is she alright?" Then the realisation hit. Something was very wrong. I knew instinctively that I had to lower Domenica's temperature, and I raced to bathe her in tepid running water. When she regained consciousness, after what seemed a very long time but was probably only a couple of minutes, I called our doctor, who finally arrived with the crisis over. Throughout the night I repeatedly roused Domenica to ensure that she was still breathing. It was a very long night. I felt that the doctor did not take the time to explain things to me. I wanted to know why it had happened, why it had come on so quickly, would it happen again. To be told that it would probably not was just not enough Karen Russo, Melbourne, Australia and prognosis of this disorder can alleviate the anxiety and let the family return to normal life. ${ }^{\text {w26 }}$

\section{Immediate management}

Acute treatment is indicated for prolonged seizures. Where a seizure continues for more than five minutes, an ambulance should be called. Acute treatments such as rectal diazepam $(0.5 \mathrm{mg} / \mathrm{kg})$ and buccal $(0.4-0.5 \mathrm{mg} /$ $\mathrm{kg})$ or intranasal $(0.2 \mathrm{mg} / \mathrm{kg})$ midazolam are effective and can be administered at home for a seizure lasting longer than five minutes. ${ }^{23}{ }^{24}$ If the seizure is not aborted after another 10 minutes, the larger jerking has stopped but the child has ongoing twitching, or another seizure begins before the child returns to normal conscious status, an ambulance should be called. Randomised controlled trials have shown that midazolam has superior efficacy to diazepam. ${ }^{2324}$ The choice of acute treatment will depend on the formulations available in different countries. Indications for providing acute treatment at home include children with a high risk of recurrence, an initial prolonged febrile seizure, or where the child is geographically isolated from medical intervention.

Paracetamol and ibuprofen are often useful in relieving the discomfort of a febrile child. However, rigorous attempts to reduce the temperature with these drugs 
should not be recommended, as no evidence exists that this decreases recurrence of febrile seizures. ${ }^{\text {w27 w28 }}$

\section{Prophylactic treatment}

No compelling evidence exists that continuous anticonvulsant drugs reduce the risk of epilepsy developing, and considerable potential side effects exist. ${ }^{5}$ Given the benign prognosis of febrile seizures, prophylactic treatment is not indicated. ${ }^{\text {w23 }}{ }^{29}$ w30 After a specialist consultation, most parents are not interested in available preventive treatment. ${ }^{25}$

Where children have recurrent prolonged febrile seizures and are geographically isolated from medical access, intermittent treatment can be considered. Randomised, double blind, placebo controlled trials have found that diazepam given during a fever reduces recurrence of febrile seizures. ${ }^{\text {w30 }}$ w31

\section{Summary}

Febrile seizures are a common benign disorder with an excellent outcome. Exclusion of central nervous system infection such as meningitis and encephalitis is important, particularly in a child with febrile status epilepticus. Education and reassurance remains the mainstay of management for families faced with these frightening attacks.

Contributors: Both authors contributed to all aspects, including searching the literature and writing the article. IES is the guarantor.

Competing interests: None declared.

1 Nelson KB, Ellenberg JH. Predictors of epilepsy in children who have experienced febrile seizures. N EnglJ Med 1976;295:1029-33.

2 Kjeldsen MJ, Kyvik KO, Friis ML, Christensen K. Genetic and environmental factors in febrile seizures: a Danish population-based twin study. Epilepsy Res 2002;51:167-77.

3 Offringa M, Bossuyt PM, Lubsen J, Ellenberg JH, Nelson KB, Knudsen FU, et al. Risk factors for seizure recurrence in children with febrile seizures: a pooled analysis of individual patient data from five studies. J Pediatr 1994;124:574-84.

4 Audenaert D, Van Broeckhoven C, De Jonghe P. Genes and loci involved in febrile seizures and related epilepsy syndromes. Hum Mutat 2006;27:391-401.

5 American Academy of Pediatrics, Committee on Quality Improvement, Subcommittee on Febrile Seizures. Practice parameter: long-term treatment of the child with simple febrile seizures. Pediatrics 1999;103:1307-9.

6 Berg AT. Are febrile seizures provoked by a rapid rise in temperature? Am J Dis Child 1993;147:1101-3.

7 Uemura N, Okumura A, Negoro T, Watanabe K. Clinical features of benign convulsions with mild gastroenteritis. Brain Dev 2002;24:745-9.

8 Berg AT, Shinnar S. Complex febrile seizures. Epilepsia 1996;37:126-33.

9 Annegers JF, Hauser WA, Shirts SB, Kurland LT. Factors prognostic of unprovoked seizures after febrile convulsions. N EnglJ Med 1987;316:493-8.

10 Narula S, Goraya JS. Febrile myoclonus. Neurology 2005;64:169-70.

11 Berg AT, Shinnar S. Unprovoked seizures in children with febrile seizures: short-term outcome. Neurology 1996;47:562-8.

12 Berg AT, Shinnar S, Darefsky AS, Holford TR, Shapiro ED, Salomon ME, et al. Predictors of recurrent febrile seizures: a prospective cohort study. Arch Pediatr Adolesc Med 1997;151:371-8.

13 Shinnar S, Glauser TA. Febrile seizures. J Child Neurol 2002;17(suppl 1):S44-52.

14 Dube C, Richichi C, Bender RA, Chung G, Litt B, Baram TZ. Temporal lobe epilepsy after experimental prolonged febrile seizures: prospective analysis. Brain 2006;129:911-22.

15 Scott RC, King MD, Gadian DG, Neville BGR, Connelly A. Hippocampal abnormalities after prolonged febrile convulsion: a longitudinal MRI study. Brain 2003;126:2551-7.

16 Sloviter RS, Kudrimoti HS, Laxer KD, Barbaro NM, Chan S, Hirsch LI, et al. "Tectonic" hippocampal malformations in patients with temporal lobe epilepsy. Epilepsy Res 2004;59:123-53.

17 Lewis DV. Losing neurons: selective vulnerability and mesial temporal sclerosis. Epilepsia 2005;46(suppl 7):39-44.

18 Chang YC, Guo NW, Wang ST, Huang CC, Tsai JJ. Working memory of school-aged children with a history of febrile convulsions: a population study. Neurology 2001;57:37-42.

19 Waruiru C, Appleton R. Febrile seizures: an update. Arch Dis Child 2004;89:751-6.

20 Chin RFM, Neville BG, Scott RC. Meningitis is a common cause of convulsive status epilepticus with fever. Arch Dis Child 2005;90:66-9.

21 American Academy of Pediatrics, Provisional Committee on Quality Improvement, Subcommittee on Febrile Seizures. Practice parameter: the neurodiagnostic evaluation of the child with a first simple febrile seizure. Pediatrics 1996;97:769-72, discussion 73-5.

22 Teng D, Dayan P, Tyler S, Hauser WA, Chan S, Leary L, et al. Risk of intracranial pathologic conditions requiring emergency intervention after a first complex febrile seizure episode among children. Pediatrics 2006;117:304-8.

23 McIntyre J, Robertson S, Norris E, Appleton R, Whitehouse WP, Phillips B, et al. Safety and efficacy of buccal midazolam versus rectal diazepam for emergency treatment of seizures in children: a randomised controlled trial. Lancet 2005;366:205-10.

24 Bhattacharyya M, Kalra V, Gulati S. Intranasal midazolam vs rectal diazepam in acute childhood seizures. Pediatr Neurol 2006;34:355-9.

25 Gordon KE, Dooley JM, Camfield PR, Camfield CS, MacSween J. Treatment of febrile seizures: the influence of treatment efficacy and side-effect profile on value to parents. Pediatrics 2001;108:1080-8.

\section{Listen very carefully}

The old slam door commuter trains on the Brighton line had a capacious luggage cage that could carry many bicycles at rush hour. The new sleek trains have a space for two bikes opposite the large super-loos. Shortly after the introduction of the new trains, before bikes were banned at rush hour, I boarded one of them at Haywards Heath for the short journey home. There were already three bikes in the allocated space and plenty of people standing, so I wedged my bike out of the way against the offside doors and got out that week's $B M J$. Some five minutes into the journey I was alerted by an announcement over the train's public address system: "Can a doctor contact the driver, please."

Did I really hear that? I had been deeply absorbed in a $B M J$ article, was I mistaken about the request? How does one contact the driver? Why the driver and not the guard? My bike was just leaning up against the doors and not strapped in as regulations required. Would it be safe to just leave it there and go and find the guard? I was in the middle of a crowded train of 12 coaches: which end was the guard in? If it was a sick passenger, why the driver and not the guard? If the driver needed a doctor, why was he still driving? Had I misheard what had been said?

By the time all these questions had gone through my mind, the train was approaching a station. If the driver or a passenger needed attention, no doubt an ambulance would be summoned and a further request for a doctor made. The train stopped, the doors opened and closed and the train pulled out of the station. Slowly it dawned on me. The announcement had been: "Conductor contact the driver, please."

Douglas Graham Heap independent dental sedationist, Lewes, East Sussex (graham_heap@btinternet.com) 